\title{
Observational evidence of quasi-27-day oscillation propagating from the lower atmosphere to the mesosphere over $20^{\circ} \mathrm{N}$
}

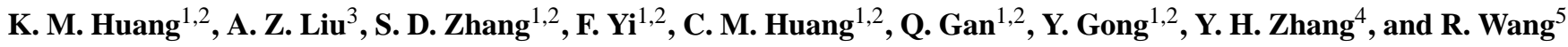 \\ ${ }^{1}$ School of Electronic Information, Wuhan University, Wuhan, China \\ ${ }^{2}$ State Observatory for Atmospheric Remote Sensing, Wuhan, China \\ ${ }^{3}$ Department of Physical Science, Embry-Riddle Aeronautical University, Daytona Beach, Florida, USA \\ ${ }^{4}$ College of Hydrometeorology, Nanjing University of Information Science and Technology, Nanjing, China \\ ${ }^{5}$ SOA Key Laboratory for Polar Science, Polar Research Institute of China, Shanghai, China
}

Correspondence to: S. D. Zhang (zsd@whu.edu.cn)

Received: 4 July 2015 - Revised: 7 September 2015 - Accepted: 14 October 2015 - Published: 30 October 2015

\begin{abstract}
By using meteor radar, radiosonde and satellite observations over $20^{\circ} \mathrm{N}$ and NCEP/NCAR reanalysis data during 81 days from 22 December 2004 to 12 March 2005, a quasi-27-day oscillation propagating from the troposphere to the mesosphere is reported. A pronounced 27-day periodicity is observed in the raw zonal wind from meteor radar. Spectral analysis shows that the oscillation also occurs in the meridional wind and temperature and propagates westward with wavenumber $s=1$; thus the oscillation is of Rossby wave type. The oscillation attains a large amplitude of about $12 \mathrm{~m} \mathrm{~s}^{-1}$ in the eastward wind shear region of the troposphere. When the wind shear reverses, its amplitude rapidly decays, and the background wind gradually evolves to be westward. However, the oscillation can penetrate through the weak westward wind field due to its relatively large phase speed. After this, the oscillation restrengthens with its upward propagation and reaches about $20 \mathrm{~m} \mathrm{~s}^{-1}$ in the mesosphere. Reanalysis data show that the oscillation can propagate to the mid and high latitudes from the low latitudes and has large amplitudes over there. There is another interesting phenomenon that a quasi-46-day oscillation appears simultaneously in the troposphere, but it cannot penetrate through the westward wind field because of its smaller phase speed. In the observational interval, a quasi-27-day periodicity in outgoing long-wave radiation (OLR) and specific humidity is found in a latitudinal zone of $5-20^{\circ} \mathrm{N}$. Thus the quasi-27day oscillation may be an atmospheric response to forcing due to the convective activity with a period of about 27 days in the tropical region.
\end{abstract}

Keywords. Meteorology and atmospheric dynamics (middle atmosphere dynamics)

\section{Introduction}

Numerous waves and oscillations with different temporal and spatial scales dominate the dynamics of the mesosphere and lower thermosphere (MLT) and play important roles in determining large-scale circulation and thermal structure of the MLT. Gravity waves are middle- and small-scale perturbations, and planetary waves are global-scale perturbations. Theoretical work indicates that planetary waves correspond to a series of eastward- or westward-propagating normal modes with periods of about 2, 5, 10 and 16 days derived from Laplace's tidal equation under an isothermal atmosphere (Andrews et al., 1987; Salby, 1984). In the realistic atmosphere, quasi-6.5-day wave can also follow the atmospheric waveguide and propagates to the mesosphere from the stratosphere (Liu et al, 2004). In general, atmospheric oscillations have longer periods than atmospheric waves. Madden and Julian (1971) discovered a 40-50-day oscillation of the zonal wind in the tropical troposphere, which is known as the Madden-Julian oscillation (MJO). Afterwards, atmospheric oscillations with a period range of about 20-100 days were reported in the light of more observational studies (Krishnamurti and Bhalme, 1976; Eckermann et al., 1997; Lieberman, 1998; Krishnan et al., 2005). For instance, significant oscillations of the tropical zonal wind at periods of about 20-30 days were found (Ghil and Mo, 1991; Ecker- 
mann et al., 1997; Luo et al., 2001). Measurements by rocket and radiosonde in the tropics showed that a 30-70-day oscillation could enter the stratosphere and strengthened in the upper stratosphere (Nagpal et al., 1994; Kumar and Jain, 1994). Eckermann and Vincent (1994) reported a 35-40-day oscillation in the equatorial MLT from medium-frequency radar observation, and Pancheva et al. (2003) revealed an oscillation with a period of 70-80 days in the MLT at mid and high latitudes based on meteor radar data.

Atmospheric oscillations attract extensive attention because of not only their important influences on monsoon, rainfall, and circulation but also their complex atmospheric processes and dynamics. Observations indicate that most of them are analogous to an eastward-propagating Kelvin wave, and the other fraction propagates westward, similar to a Rossby wave. Although it is generally accepted that these oscillations are originally generated in the tropical lower atmosphere, their complexity is also evidenced by a wide range of possible generation mechanisms suggested by previous studies, including atmospheric response to stationary and stochastic forcing, atmospheric instability, activity of deep convection and water vapor, and scale interaction (Zhang, 2005). In the troposphere, the oscillation showed significant vertical variations in the amplitude and period (Rao et al., 2000; Deshpande et al., 2011) and can propagate into the stratosphere due to transmission through the tropical tropopause (Kumar and Jain, 1994). As for the oscillation observed in the MLT, Eckermann and Vincent (1994) argued that it did not come from the lower atmosphere. Instead, they proposed that gravity waves and nonmigrating tides produced by tropical convection were modulated by the oscillation in the lower atmosphere and then induced the similar period oscillation in the MLT by propagating to the MLT and dissipating their energy and momentum into the mean flow (Eckermann and Vincent, 1994; Eckermann et al., 1997). However, exact cause of the oscillation observed in the MLT at mid and high latitudes remains unknown (Pancheva et al., 2003). The origin and dynamics of the oscillation in the MLT deserves our further attention.

In this paper, we will present the evidence of a quasi-27day oscillation propagating from the troposphere to the MLT over $20^{\circ} \mathrm{N}$ based on radar and radiosonde observations, and we will investigate possible generation sources of the observed oscillation.

Data and analysis methods are described in Sect. 2. In Sect. 3, propagation and structure of the oscillation at a period of about 27 days are studied. In Sect. 4, the excitation source of the oscillation is discussed. Section 5 presents a summary.

\section{Data and analysis methods}

\subsection{Data}

In present paper, the horizontal wind measured by Maui meteor radar for 81 days from 22 December 2004 to 12 March 2005 is utilized. The meteor radar located in Kihei on Maui, Hawaii, at $20.75^{\circ} \mathrm{N}, 156.43^{\circ} \mathrm{W}$, is an all-sky interferometric meteor radar (SKiYMET) (Hocking et al., 2001), operating at $40.92 \mathrm{MHz}$. The meteor trails were illuminated by a threeelement Yagi antenna directed toward the zenith with an average transmitted power of approximately $170 \mathrm{~W}$, which resulted from a $13.3 \mu$ s pulse length, $6 \mathrm{~kW}$ peak envelope power and a $466 \mu$ interpulse period. The meteor trail reflections were detected by five three-element Yagi antennas oriented along two orthogonal baselines, with one antenna in the array center and four outer antennas separated from the center antenna by 1.5 and 2.0 wavelengths. The receiving antennas were sampled every $13.3 \mu \mathrm{s}$, resulting in a $2 \mathrm{~km}$ range resolution. By using a weighted least-squares fit, the horizontal wind velocities were determined from the trail positions and Doppler shifts in a $1 \mathrm{~h}$ time and $4 \mathrm{~km}$ height bin under the condition that the vertical speed was negligible, and then the hourly vertical profiles were oversampled at a $1 \mathrm{~km}$ height interval in the range from 80 to $100 \mathrm{~km}$. The detection rate of meteors showed a strong dependence on altitude, and most echoes were detected around $90 \mathrm{~km}$. The wind data from 82 to $96 \mathrm{~km}$ will be analyzed because of their small amount of missing data. At these heights, the largest rate of missing data is $1.34 \%$ ( 26 points) with the longest data gap of $20 \mathrm{~h}$ at $82 \mathrm{~km}$ during 81 days. The Maui radar system and the horizontal wind calculation were detailedly described in previous work (Franke et al., 2005). The meteor radar observation has been applied to the investigation of tides and planetary waves in the MLT over Maui (Huang et al., 2013a, b).

We use the high-resolution United States radiosonde data during the observational period mentioned above in Hilo $\left(19.72^{\circ} \mathrm{N}, 155.07^{\circ} \mathrm{W}\right)$ in Hawaii, and in Cold Bay $\left(55.20^{\circ} \mathrm{N}, 162.72^{\circ} \mathrm{W}\right)$ in Alaska. The data can be freely accessed from National Climatic Data Center (NCDC) of National Oceanic and Atmospheric Administration (NOAA) through the Stratospheric Processes and Their Role in Climate (SPARC) Data Center at http://www.sparc.sunysb.edu/. Routine radiosondes are usually launched twice daily at 00:00 and 12:00 UT. In each sounding, accompanied by the balloon ascent, temperature, pressure, relative humidity, and horizontal wind were sampled at irregular height resolutions, ranging from tens to hundreds of meters. For convenience, the raw data are processed to have a $50 \mathrm{~m}$ height resolution by linear interpolation. The altitude range of radiosonde observation depends on balloon burst height. In 162 measurements during 81 days, about 92 and $81 \%$ of balloons reach an altitude of $32 \mathrm{~km}$ in Hilo and Cold Bay, respectively, but only about 74 and $76 \%$ attain $33 \mathrm{~km}$. We choose the altitude 
of $32 \mathrm{~km}$ as the upper height limit of analysis to ensure that more than $80 \%$ of balloons can reach this level.

The National Centers for Environmental Prediction/National Center for Atmospheric Research (NCEP/NCAR) reanalysis data (Kalnay et al., 1996) and interpolated outgoing long-wave radiation (OLR) data are used to investigate the oscillation that we focus on. These data are provided by the NOAA/OAR/ESRL PSD, Boulder, Colorado, USA, from their Web site at http://www.esrl.noaa.gov/psd/. These data have a $2.5^{\circ}$ latitudinal and longitudinal resolution. Horizontal wind in reanalysis data is at 17 pressure levels from 1000 to $10 \mathrm{hPa}$ levels, while specific humidity is at 8 pressure levels from 1000 to $300 \mathrm{hPa}$ levels. The daily data of zonal wind, specific humidity and OLR are employed in this study. Specific humidity is often referred to as water vapor mixing ratio, too. Solar radio flux at $10.7 \mathrm{~cm}$ (F10.7) and geomagnetic $\mathrm{Kp}$ index data from NGDC/NOAA at https://www.ngdc.noaa.gov/ are utilized to examine the relationship between the oscillation and solar and geomagnetic activities.

Additionally, we employ Thermosphere, Ionosphere, Mesosphere, Energetics and Dynamics/Sounding of the Atmosphere using Broadband Emission Radiometry (TIMED/SABER) temperature measurements from version 1.07, which are downloaded through the online data access of http://saber.gats-inc.com/. The temperature data in the latitudinal zone of $18.75-22.75^{\circ} \mathrm{N}$ are chosen to support our study. All of the data utilized are from 22 December 2004 to 12 March 2005, and we refer to 22 December 2004 as day 1 in the following.

\subsection{Analysis methods}

Lomb-Scargle spectrum analysis applies to unevenly sampled data (Scargle, 1982). Considering that there are a small amount of missing data in radar and radiosonde observations, a Lomb-Scargle spectrum analysis, with a 4 times oversampling corresponding to an effective frequency resolution of $1 / 324 \mathrm{cpd}$, is performed on the 81 -day data observed by meteor radar and radiosonde to decompose their spectral components. A similar spectral analysis is also carried out for F10.7 and Kp index data. Meanwhile, to estimate the oscillation parameters, we make a fitting of sinusoidal wave on the 81-day wind series in which the linear trend is removed.

The reanalysis data of zonal wind over $20^{\circ} \mathrm{N}$ are a twodimensional regular array; thus we can make a discrete Fourier transform to obtain its frequency-wavenumber spectrum. As for the irregularly sampled SABER temperature data, a least-squares fitting method of spectral analysis of space-time series proposed by Wu et al. (1995) is adopted. The fitting step is set to be 0.5 in wavenumber and 0.5 day in corresponding period. These frequency-wavenumber spectra derived from the discrete Fourier transform and the leastsquares fitting are normalized by their maximum values, re-
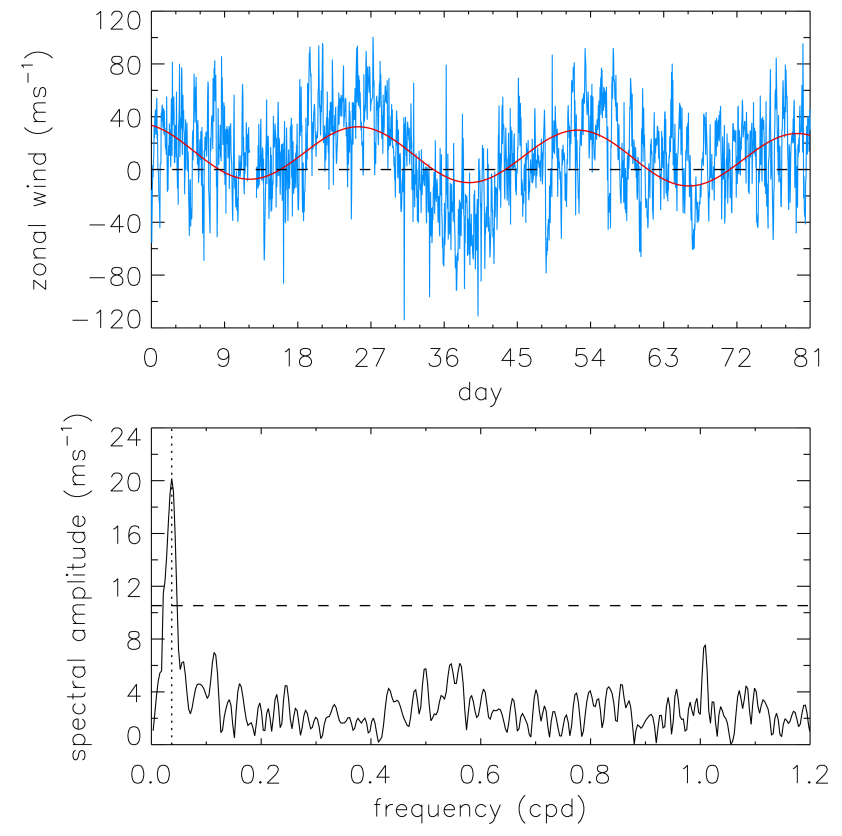

Figure 1. Top: zonal wind observed with Maui meteor radar and fitted oscillation at $90 \mathrm{~km}$ for 81 days. The blue line denotes the measured wind, and the red line denotes the sum of fitted oscillation and linear trend. Bottom: Lomb-Scargle spectrum of zonal wind at $90 \mathrm{~km}$. The dotted vertical line denotes the spectral component corresponding to a period of 27 days, and the dashed horizontal line denotes the confidence level of $95 \%$.

spectively, and then are shown as the corresponding periodwavenumber spectra.

Finally, a wavelet analysis is used to investigate the spectral information of OLR and specific humidity. Wavelet analysis has the advantage of determining both the dominant modes and how these modes vary with time. In the present study, Morlet wavelet function consisting of a plane wave modulated by a Gaussian envelope is chosen as a mother wavelet.

\section{Quasi-27-day oscillation}

\subsection{Oscillation in MLT}

Figure 1 shows the zonal wind (positive eastward) at the height of $90 \mathrm{~km}$ from meteor radar observation. One can note an obvious quasi-27-day oscillation in the raw wind field. The Lomb-Scargle spectrum of the zonal wind is also shown in Fig. 1. The dotted vertical line in Fig. 1 corresponds to a period of 27 days. As expected, the 27-day oscillation is a dominant component in the zonal wind field. Now that the 27-day periodicity is so remarkable, a 27-day sinusoidal wave fitting is carried out, and the fitted wave is plotted in Fig. 1. The fitted amplitude is about $20 \mathrm{~m} \mathrm{~s}^{-1}$, which coincides with the spectral amplitude shown in Fig. 1. This in- 


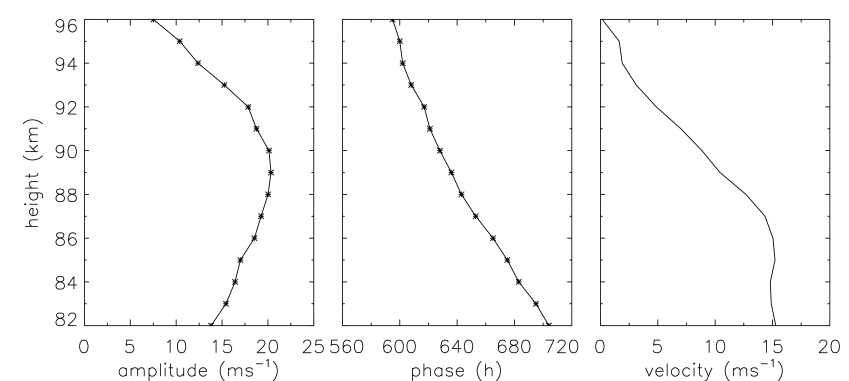

Figure 2. Left: amplitude of oscillation in zonal wind at $82-96 \mathrm{~km}$ over Maui. Middle: phase of oscillation. Right: averaged zonal wind. The asterisks represent the fitted values.

dicates that the 27-day oscillation can attain a mean magnitude of about $20 \mathrm{~m} \mathrm{~s}^{-1}$ in a period as long as 81 days. Thus this is a strong oscillation, relative to previously reported 20-40-day oscillation with amplitudes of 5-10 $\mathrm{m} \mathrm{s}^{-1}$ around $90 \mathrm{~km}$ (Luo et al., 2001). In order to determine the vertical propagation characteristic of the oscillation, the fitting is applied to the zonal winds in the height range from 82 to $96 \mathrm{~km}$. Figure 2 shows the evolutions of the oscillation amplitude and phase with height. Here, the phase is denoted by the time when the oscillation reaches the maximum velocity. The oscillation amplitude increases from $13.8 \mathrm{~m} \mathrm{~s}^{-1}$ at $82 \mathrm{~km}$ to its maximum value of $20.3 \mathrm{~m} \mathrm{~s}^{-1}$ at $89 \mathrm{~km}$ and then decreases to $7.5 \mathrm{~m} \mathrm{~s}^{-1}$ at $96 \mathrm{~km}$. The rapid decay in the amplitude might have a close relation to intense eddy diffusion in the mesopause region and energy exchange between the oscillation and the shear wind (Huang et al., 2010, 2014). The oscillation phase exhibits a feature of downward progression, implying that the quasi-27-day oscillation propagates upward.

A similar analysis of the meridional wind indicates that the quasi-2-day wave is a dominant component, as reported by previous studies (Zhou et al., 1997; Jacobi et al., 2001; Huang et al., 2013b), and the quasi-27-day oscillation with maximum amplitude of about $5.6 \mathrm{~m} \mathrm{~s}^{-1}$ at $86 \mathrm{~km}$ is much weaker than the quasi-2-day wave. According to the spacetime series of the TIMED/SABER temperature over $20^{\circ} \mathrm{N}$, we can obtain their frequency-wavenumber spectra at 82 $96 \mathrm{~km}$, which shows that the strongest temperature oscillation occurs at $85 \mathrm{~km}$ with spectral amplitude of about $2.0 \mathrm{~K}$. Figure 3 presents the normalized period-wavenumber spectrum at $85 \mathrm{~km}$. Figure 3 clearly demonstrates that the quasi27 -day oscillation has a westward wavenumber $s=1$. The quasi-27-day oscillation occurs in the zonal and meridional winds and temperature and propagates westward; thus the quasi-27-day oscillation shows a feature of Rossby wave. Considering that the oscillation is intense in the zonal wind, we will focus our attention on it only in the zonal wind.

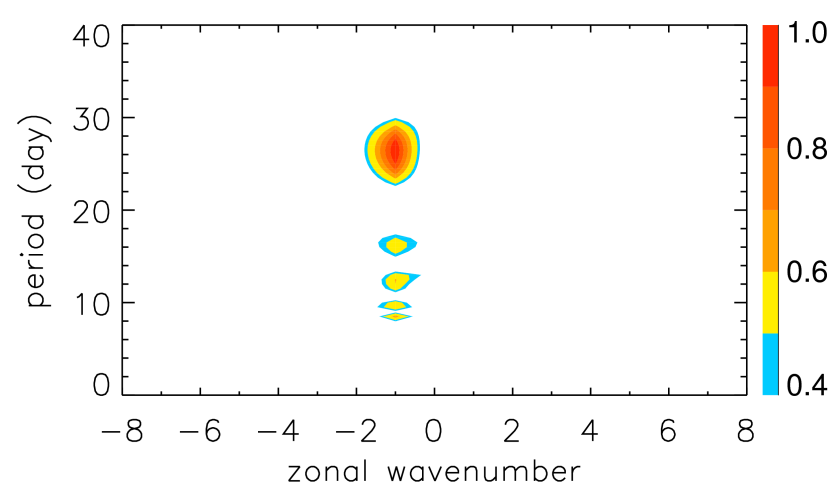

Figure 3. Normalized period-wavenumber spectrum of TIMED/SABER temperature at $85 \mathrm{~km}$ over $20^{\circ} \mathrm{N}$.

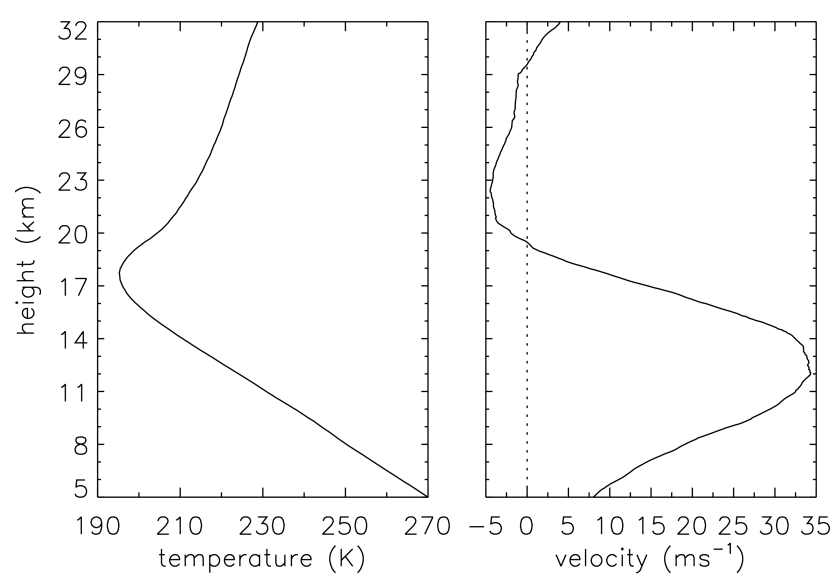

Figure 4. Averaged (left) temperature and (right) zonal wind at 5$32 \mathrm{~km}$ from radiosonde observations over Hilo.

\subsection{Oscillation in lower atmosphere}

We analyze the radiosonde data at the station of Hilo to investigate the activity of the oscillation in the troposphere and lower stratosphere. Hilo is only about $1^{\circ}$ latitude and longitude away from Maui. Figure 4 shows the average of the 81-day temperature and zonal wind at the heights of 5-32 km over Hilo. One can see the tropopause located at about $17.7 \mathrm{~km}$ and a weak westward wind region above the tropopause, with a maximum speed of about $4.5 \mathrm{~m} \mathrm{~s}^{-1}$ at $22.5 \mathrm{~km}$. Figure 5 shows the Lomb-Scargle spectrum of the zonal wind, which illustrates that the quasi-27-day oscillation is particularly notable and can penetrate through the tropopause to enter the stratosphere. In the troposphere, the oscillation has a relatively wide spectral band, and its amplitude and period exhibit the changes with height, which is consistent with earlier studies (Rao et al., 2000; Deshpande et al., 2011). As shown in Fig. 4, the background wind shear is westward between $12 \mathrm{~km}$ and $22.5 \mathrm{~km}$ and eastward beyond this height range. A numerical study (Huang et al., 2008, 2010) indicated that when a wave propagates in 


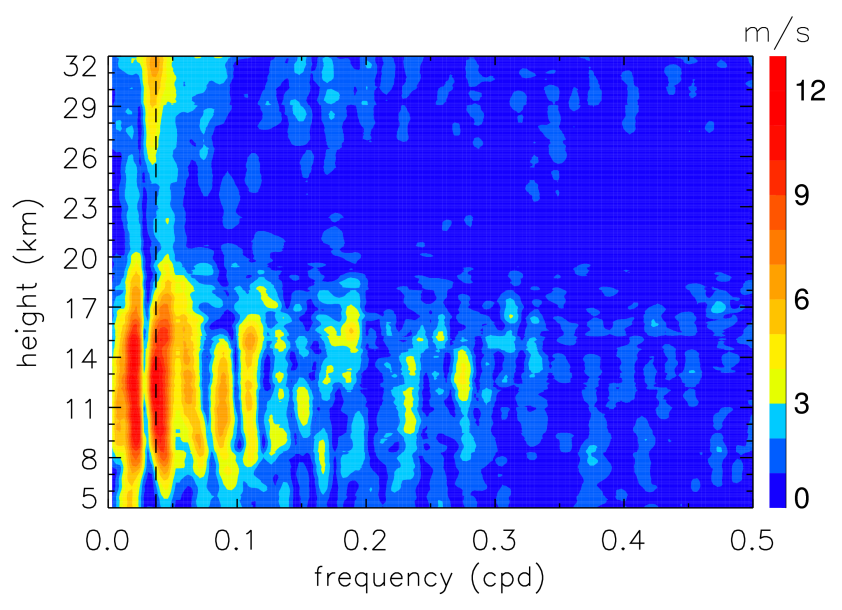

Figure 5. Lomb-Scargle spectrum of zonal wind at 5-32 km from radiosonde observations over Hilo. The dotted vertical line corresponds to a period of 27 days.

a shear flow, energy exchange occurs between the wave and the background flow because of the work due to the Reynolds stress. The wave propagating against (along) the wind shear can absorb (transfer) energy from (to) the flow. We can see from Fig. 5 that below $12 \mathrm{~km}$ the spectral amplitude increases with height and attains a maximum value of $12.2 \mathrm{~m} \mathrm{~s}^{-1}$ at $12 \mathrm{~km}$ because the oscillation propagates against the wind shear. Subsequently, as the reverse of the wind shear, its spectral amplitude gradually drops to about $2.4 \mathrm{~m} \mathrm{~s}^{-1}$ at $22.8 \mathrm{~km}$. After this, with the reverse of the wind shear again, its amplitude restrengthens and increases to about $6.7 \mathrm{~m} \mathrm{~s}^{-1}$ at $32 \mathrm{~km}$. We can easily estimate that the zonal phase speed of the quasi-27-day oscillation at a low latitude of $20^{\circ} \mathrm{N}$ is slightly larger than the westward zonal wind. Thus its partial component may penetrate through the tropopause and the weak westward wind region and propagates vertically to the stratosphere, as shown in Fig. 5. Meanwhile, because of the effect of the background atmosphere, the oscillation evolves to be an oscillation with a dominant period of 27 days above $29 \mathrm{~km}$, especially in the MLT region, as shown in Fig. 1. In spite of the lack of observational data at the altitude range of about $32-82 \mathrm{~km}$, we could infer the upward propagation of the oscillation based on the coherently downward progression of its phase. The averaged zonal wind at $82-96 \mathrm{~km}$ is presented in Fig. 2. The weak eastward wind is also suitable for the upward propagation of the oscillation. Therefore, the quasi-27-day oscillation is generated in the troposphere and propagates upward to the MLT.

Figure 5 exhibits another interesting phenomenon. There is also a strong quasi-46-day oscillation with spectral amplitudes comparable to the quasi-27-day oscillation at 5-20 km. The quasi-46-day oscillation is more sensitive to the westward wind field because it has a smaller phase speed. Hence, Fig. 5 indicates that although the quasi-46-day oscillation can overcome the tropopause block to leak into the lower strato-
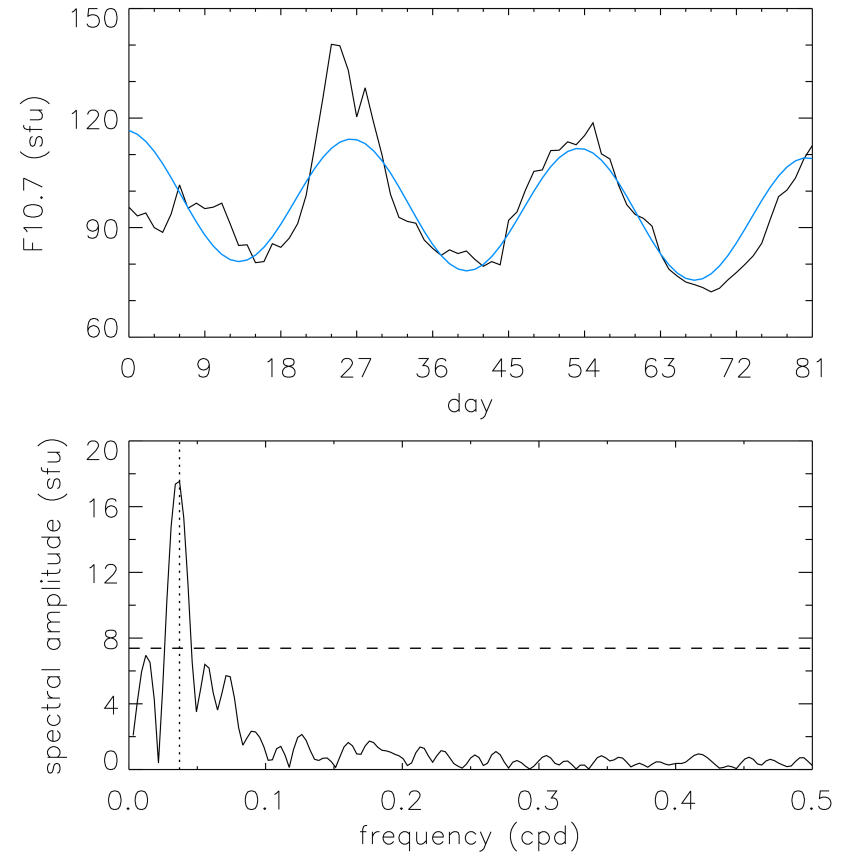

Figure 6. Top: solar $10.7 \mathrm{~cm}$ flux from NGDC and fitted oscillation. The black line denotes F10.7, and the blue line denotes the sum of fitted oscillation and linear trend. Bottom: Lomb-Scargle spectrum of F10.7. The dotted vertical line corresponds to a period of 27 days, and the dashed horizontal line denotes the confidence level of $95 \%$.

sphere, it does not penetrate through the westward wind region. Thus we cannot observe an obvious spectral component of about 46-day period above $26 \mathrm{~km}$, including in the MLT, as shown in Fig. 1.

The quasi-27-day oscillation may have a significant influence on plasma motion by neutral-plasma interaction in the lower thermosphere. Considering that the plasma is modulated by solar radiation intensity and geomagnetic activity, we analyze the relationship between the oscillation and solar radiation and geomagnetic parameters. Here, F10.7 and Kp index are used as proxies for solar radiation and geomagnetic activity, respectively. Figures 6 and 7 present the F10.7 and daily averaged $\mathrm{Kp}$ index variations and their Lomb-Scargle spectra. In our observational interval, F10.7 has a dominant 27-day period, while Kp index does not show a 27 -day periodicity, and a near and weak spectral peak appears at a period of about 21.6 days. Figure 8 exhibits the fitted oscillations in the zonal winds at 32 and $90 \mathrm{~km}$ and F10.7. One can see from Fig. 8 that the oscillation in F10.7 is almost in phase with that in the zonal wind at $90 \mathrm{~km}$ but nearly anti-phase with that in the zonal wind at $32 \mathrm{~km}$. The quasi-27-day oscillation has a possible connection with solar activity. The plasma activity may be complex because it is affected not only by neutralplasma interaction and solar radiation but also by geomagnetic activity.

Finally, the reanalysis data of daily zonal wind at $10 \mathrm{hPa}$ level are used to further investigate the structure and prop- 

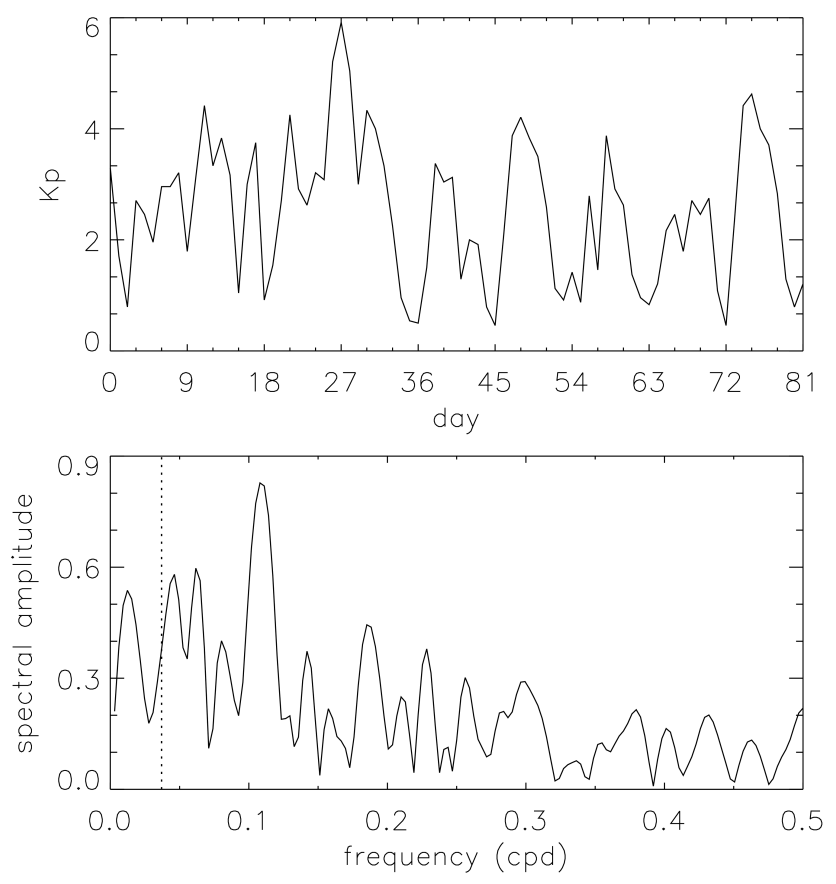

Figure 7. Top: daily averaged Kp index. Bottom: its Lomb-Scargle spectrum. The dotted vertical line corresponds to a period of 27 days.

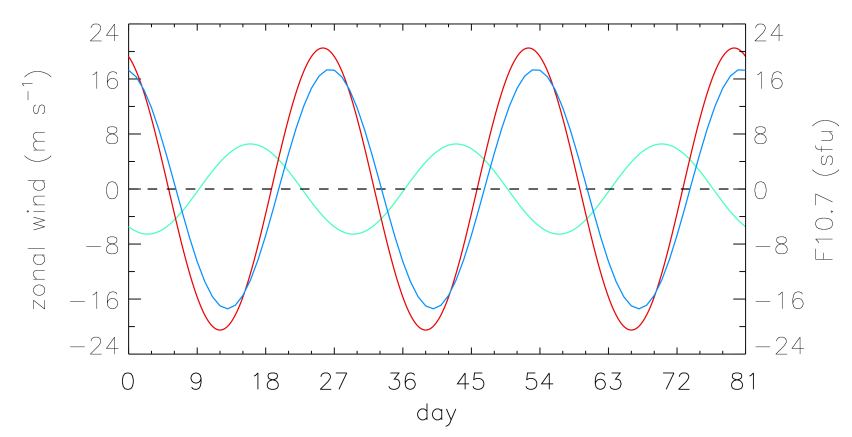

Figure 8. Fitted oscillations of zonal winds at (red) $90 \mathrm{~km}$ and (green) $32 \mathrm{~km}$, and (blue) F10.7.

agation of the quasi-27-day oscillation. Figure 6 shows the zonal wind disturbance at $10 \mathrm{hPa}$ corresponding to a slightly changed altitude range from 30.85 to $31.95 \mathrm{~km}$ over $20^{\circ} \mathrm{N}$ during 81 days. The zonal wind disturbance is calculated from the zonal wind by subtracting its zonally averaged value. A westward-propagating quasi-27-day perturbation clearly appears in Fig. 9. Figure 9 also presents the normalized period-wavenumber spectrum of the zonal wind disturbance derived from a discrete Fourier transform. As expected, the quasi-27-day oscillation is a dominant component with westward wavenumber $s=1$, which is in good agreement with the result of the TIMED/SABER temperature, as shown in Fig. 3. In addition, a relatively weak quasi-16-day wave with westward wavenumber $s=1$ can also be observed
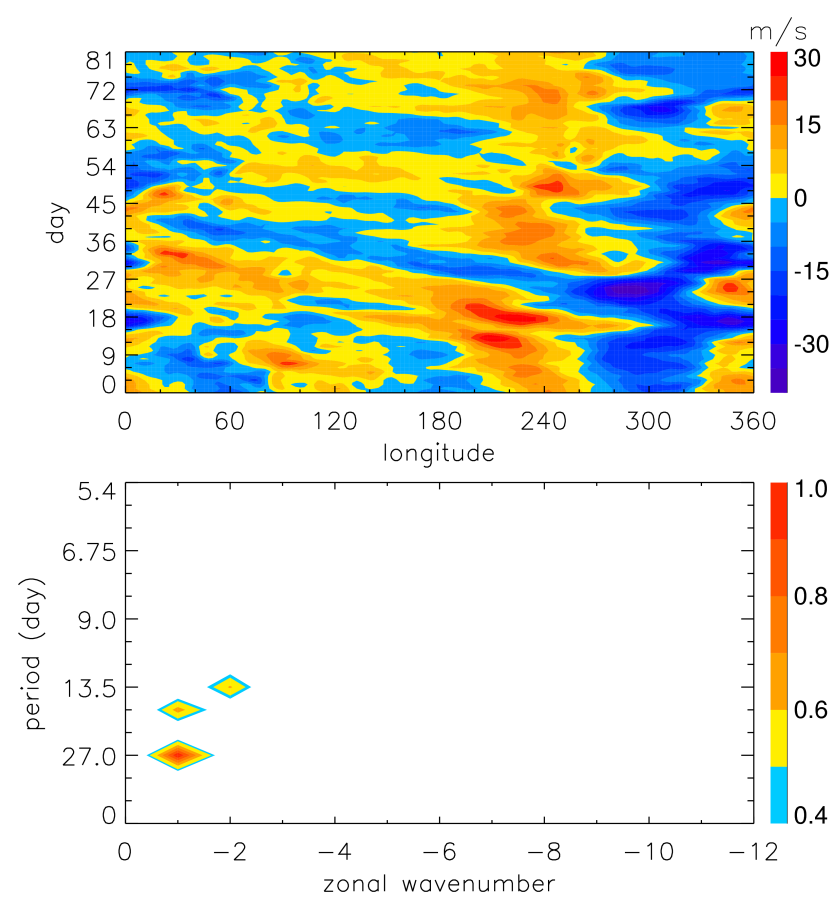

Figure 9. Top: zonal wind disturbance at $10 \mathrm{hPa}$ over $20^{\circ} \mathrm{N}$ derived from NCEP/NCAR reanalysis data. Bottom: normalized periodwavenumber spectrum of zonal wind disturbance.

from Figs. 3 and 9. Further, for the sake of exploring the meridional characteristic of the oscillation, we choose the data of the zonal wind at $10 \mathrm{hPa}$ on day 27 in the Northern Hemisphere to perform a sinusoidal wave fitting since the oscillation is intense on day 27, as shown in Fig. 9. Figure 10 shows the meridional variations of the oscillation amplitude and phase. Here, the phase is denoted by the latitude at which the velocity of the oscillation reaches the maximum. Starting from $5^{\circ} \mathrm{N}$, the phase increases with latitude. Thus the oscillation propagates northward, which is consistent with earlier observational and modeling studies. In a word, the quasi-27day oscillation is generated in the tropical troposphere and propagates northwestward and upward. Figure 10 indicates that the oscillation amplitude exhibits two obvious peaks located at 27.5 and $50^{\circ} \mathrm{N}$ with the values of about 21 and $30 \mathrm{~m} \mathrm{~s}^{-1}$, respectively. The radiosonde observation in Cold Bay is used to confirm the occurrence of oscillation in the mid and high latitudes. Figure 11 shows the Lomb-Scargle spectrum of the zonal wind disturbance at $31 \mathrm{~km}$ over Cold Bay. As expected, the spectral amplitude of about $10 \mathrm{~m} \mathrm{~s}^{-1}$ in Cold Bay is obviously larger than that of about $6.4 \mathrm{~m} \mathrm{~s}^{-1}$ at $31 \mathrm{~km}$ in Hilo. Hence, the oscillation can propagate to the mid and high latitudes and may have large amplitudes over there. 


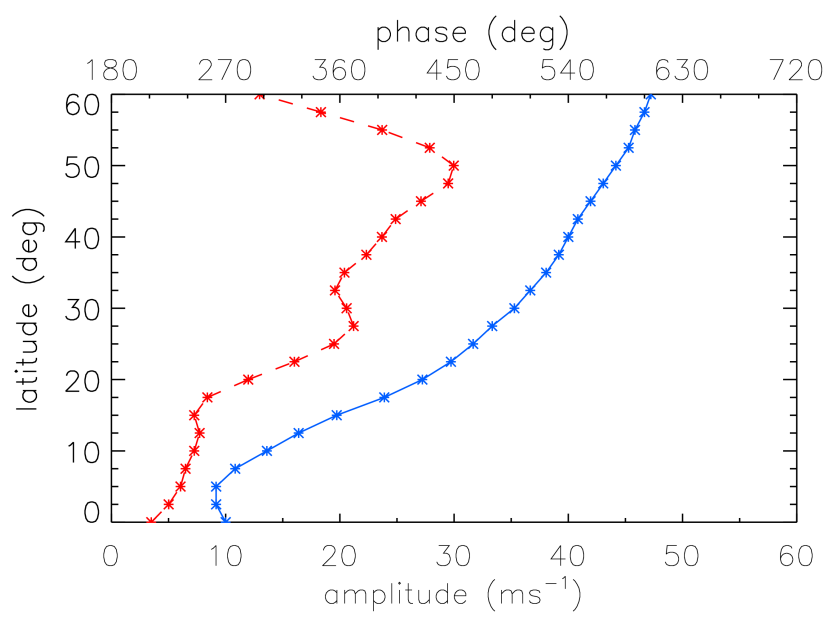

Figure 10. Evolutions of (red) amplitude and (blue) phase of oscillation with latitude. The asterisks represent the fitted values.

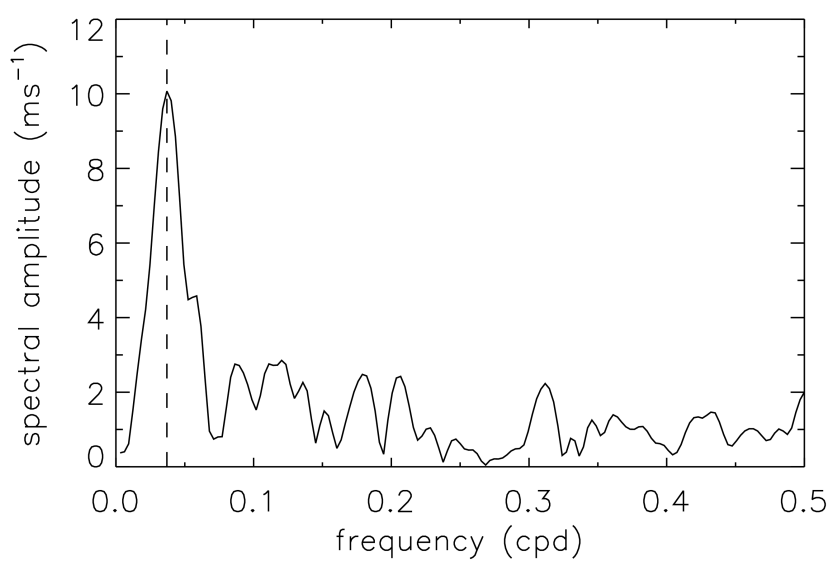

Figure 11. Lomb-Scargle spectrum of zonal wind disturbance at $31 \mathrm{~km}$ from radiosonde observations over Cold Bay. The dotted vertical line corresponds to a period of 27 days.

\section{Discussion}

It is well known that F10.7 exhibits an evident 27-day periodicity throughout the year due to the 27-day rotation of the Sun (Takahashi et al., 2010; Gasperini and Forbes, 2014). As the mesopause is the coldest region in the atmospheric temperature profile, it is impossible for the strong quasi-27-day oscillation in the MLT observed by meteor radar to be driven through direct absorption of solar radiation in the local region though the oscillation in the zonal wind near the mesopause is in phase with that in F10.7, as shown in Fig. 8. Jacobi (1998) investigated the 11-year solar cycle dependence of the wind in the MLT and found that this relation seems to be due to a forcing from below. Our analysis indicates that the quasi27-day oscillation in the MLT comes from the troposphere; thus the direct forcing source should be in the lower atmosphere.

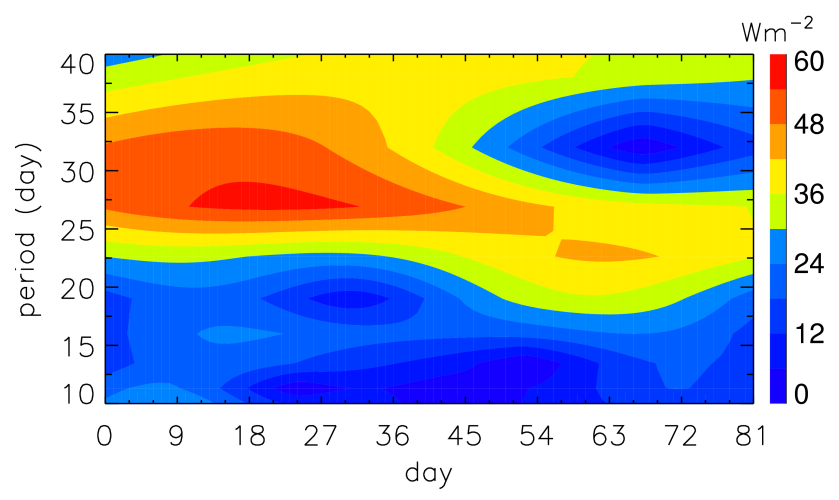

Figure 12. Wavelet spectrum of OLR at $157.5^{\circ} \mathrm{W}$ (averaged over $5-20^{\circ} \mathrm{N}$ ) from NCEP/NCAR-interpolated OLR data.

The activity of tropospheric convection in the tropical atmosphere is revealed to be an important excitation source of oscillations in previous studies, in particular, cumulus convection over the Indian Ocean and western Pacific regions (Kang et al., 2010). OLR is generally used as a proxy for convective activity. Takahashi et al. (2010) find that the yearly spectra of OLR are characterized by two peaks. One is in the period range of 40-60 days, which corresponds to the 4050-day MJO, indicating some possible connection between them. The other is relatively complex and exists at the period of about 27 days for the maximum years of solar activity but shifts to the period of about 35 days for the minimum years. Although the time interval that we focus on is not within the solar maximum years (Takahashi et al., 2010), we can examine the characteristic of OLR in a short term of 81 days. In view of the phase feature shown in Fig. 10, we analyze the averaged OLR over 5 to $20^{\circ} \mathrm{N}$ at different longitudes. Figure 12 shows the wavelet amplitude spectrum of OLR at $157.5^{\circ} \mathrm{W}$, close to Maui at $156.43^{\circ} \mathrm{W}$. One can see from Fig. 12 that OLR clearly exhibits a quasi-27-day period. Figure 13 shows the wavelet spectra of OLR at 30, 70 , and $150^{\circ} \mathrm{E}$. We choose these three longitudes to represent the tropical Africa, Indian Ocean and western Pacific regions. The periodicity of about 27 days appears in the three tropical regions. The spectral amplitude is the strongest over the western Pacific region, which agrees with earlier studies (Takahashi et al., 2010), indicating the tropical western Pacific is an important excitation region of oscillation. The quasi-27-day oscillation in OLR over the tropical Africa has the same magnitude as that over the Indian Ocean but lasts for a longer time. Thus the convective activity in the tropical Africa is also likely to play a significant role in the oscillation excitation. In addition, we perform a wavelet transform on specific humidity integrated at the lowest three pressure levels over 5 to $20^{\circ} \mathrm{N}$ in the western Pacific since the oscillation in OLR is extremely intense in this region. Figure 14 shows the wavelet spectrum of the specific humidity, which demonstrates a quasi-27-day oscillation in water vapor. This means 

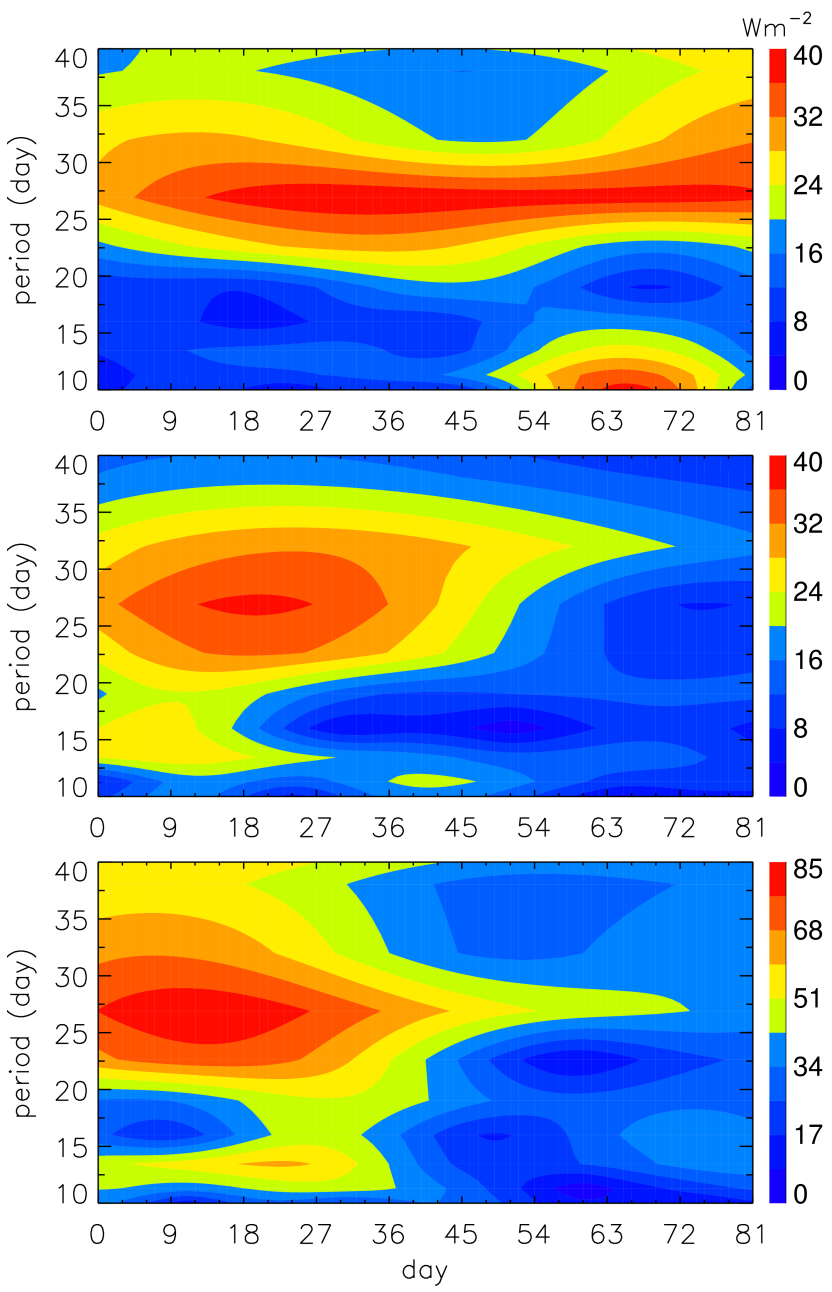

Figure 13. Wavelet spectrum of OLR at (top) $30^{\circ} \mathrm{E}$, (middle) $70^{\circ} \mathrm{E}$ and (bottom) $150^{\circ} \mathrm{E}$ (averaged over $5-20^{\circ} \mathrm{N}$ ) from NCEP/NCARinterpolated OLR data.

that a quasi-27-day oscillation in the convective activity rises over 5 to $20^{\circ} \mathrm{N}$ during 81 days, which excites a corresponding oscillation in the tropical atmosphere. We can note that the oscillation in OLR and water vapor has abundant components around the 27-day period. Accordingly, the oscillation of the tropospheric zonal wind also exhibits a similar characteristic. Moreover, according to the line wave theory (Andrews et al., 1987), there is a quasi-27-day normal mode in the atmosphere, as shown in their Fig. 4.2(b). Therefore, the strong 27-day oscillation may be an atmospheric response to forcing due to the convective activity with a period around 27 days in the tropical region. The 27-day periodicity in OLR is possibly in connection with the solar radio flux variation caused by its 27 -day rotation; however, some physical processes between them need to be clarified further, as proposed by Takahashi et al. (2010).

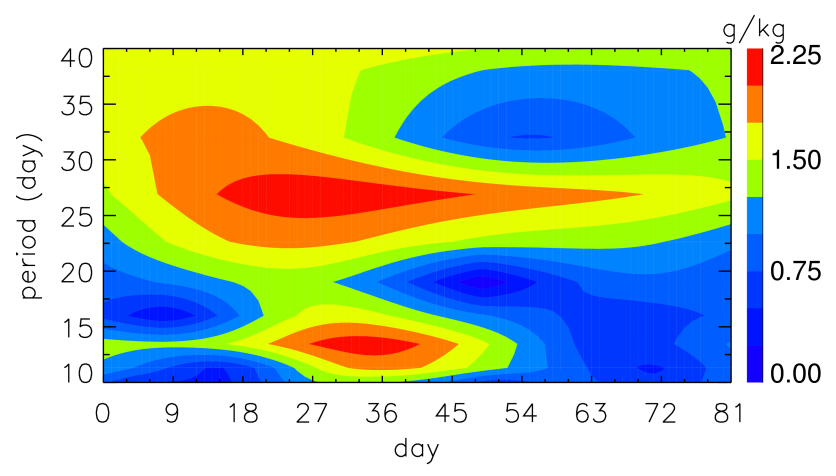

Figure 14. Wavelet spectrum of specific humidity at $150^{\circ} \mathrm{E}$ (averaged over $5-20^{\circ} \mathrm{N}$ ) from NCEP/NCAR reanalysis data.

\section{Summary}

In this paper, a quasi-27-day oscillation propagating from the troposphere to the mesosphere over $20^{\circ} \mathrm{N}$ is studied based on meteor radar, radiosonde and satellite observations and NCEP/NCAR reanalysis data. The quasi-27-day oscillation can be observed in the zonal and meridional winds and temperature and propagates westward with wavenumber $s=1$; thus the oscillation is of Rossby wave type.

In the troposphere, the oscillation has a relatively wide frequency band around a period of 27 days and attains a large amplitude of about $12 \mathrm{~m} \mathrm{~s}^{-1}$ in the eastward wind shear region. When the oscillation passes through the tropopause and propagates in the westward wind region, its spectral amplitude rapidly decreases to about $2.4 \mathrm{~m} \mathrm{~s}^{-1}$. Because its zonal phase speed is slightly larger than the westward wind, the oscillation can penetrate through the weak westward wind. After this, the oscillation strengthens with its upward propagation again. Above $29 \mathrm{~km}$, the oscillation remains a predominant period of 27 days, and the amplitude increases from $6.7 \mathrm{~m} \mathrm{~s}^{-1}$ at $32 \mathrm{~km}$ to about $20 \mathrm{~m} \mathrm{~s}^{-1}$ in the mesosphere. It is interesting that the oscillation at $90 \mathrm{~km}$ is almost in phase with the 27-day oscillation in F10.7, while the oscillation at $32 \mathrm{~km}$ is nearly anti-phase with the oscillation in F10.7. Eckermann and Vincent (1994) proposed that long period oscillations cannot propagate to the MLT from the lower atmosphere, such as the quasi-46-day oscillation shown in Fig. 5. This quasi-27-day oscillation is a short-period oscillation, with a relatively large phase speed and also exhibits the feature of Rossby wave; thus it can penetrate through the weak atmospheric wind field to propagate into the MLT. In addition, the quasi-27-day oscillation can propagate to the mid and high latitudes from the low latitudes and reaches large amplitudes over there.

Earlier studies reported that the tropical convection was an important forcing source of oscillations. The analysis indicates that a quasi-27-day oscillation in OLR occurs in a wide latitudinal zone of 5-20 $\mathrm{N}$, and a 27-day dominant periodicity is observed in specific humidity. Since a quasi-27- 
day perturbation is a possible normal mode in the atmosphere (Andrews et al., 1987), the quasi-27-day oscillation may be an atmospheric response to forcing due to the convective activity in the tropical troposphere. The 27-day periodicity in the convective activity is probably related to the solar radio flux variability, and the physical processes between them are in need of further investigation in the future.

Acknowledgements. The authors thank the editor and anonymous reviewers for their comments on the manuscript, and they are also grateful to the United States SPARC data center for providing radiosonde data, the NOAA/OAR/ESRL PSD for providing NCEP reanalysis data, the DDC/NOAA for providing F10.7 and Kp index data, and the researchers of TIMED/SABER satellite for providing online data access without charge. This work was jointly supported by the National Natural Science Foundation of China through grants 41174133, 41474127 and 41221003 as well as the National Basic Research Program of China (grant 2012CB825605).

The topical editor A. J. Kavanagh thanks two anonymous referees for help in evaluating this paper.

\section{References}

Andrews, D. G., Holton, J. R., and Leovy, C. B.: Middle Atmosphere Dynamics, Academic Press, London, 1987.

Deshpande, S. M., Raj, P. E., and Konwar, M.: Vertical variation of low-frequency oscillations in UHF radar derived winds at a tropical Indian station, J. Geophys. Res., 116, D24125, doi:10.1029/2011JD016226, 2011.

Eckermann, S. D. and Vincent, R. A.: First observation of intraseasonal wind variability in the equatorial mesosphere and lower thermosphere, Geophys. Res. Lett., 21, 265-268, 1994.

Eckermann, S. D., Rajopadhyaya, D. K., and Vincent, R. A.: Intraseasonal wind variability in the equatorial mesosphere and lower thermosphere: Long-term observations from central Pacific, J. Atmos. Sol.-Terr. Phys., 59, 603-627, 1997.

Franke, S. J., Chu, X., Liu, A. Z., and Hocking, W. K.: Comparison of meteor radar and $\mathrm{Na}$ Doppler lidar measurements of winds in the mesosphere region above Mauii, Hawaii, J. Geophys. Res., 110, D09S02, doi:10.1029/2003JD004486, 2005.

Gasperini, F. and Forbes, J. M.: Lunar-solar interactions in the equatorial electrojet, Geophys. Res. Lett., 41, 3026-3031, doi:10.1002/2014GL059294, 2014.

Ghil, M. and Mo, K.: Intraseasonal oscillation in the global atmosphere. Part I: norther hemisphere and tropics, J. Atmos. Sci., 48, 752-779, 1991.

Hocking, W. K., Fuller, B., and Vandepeer, B.: Real-time determination of meteor-related parameters utilizing modern digital technology, J. Atmos. Sol. Terr.-Phy., 63, 155-169, 2001.

Huang, K. M., Zhang, S. D., and Yi, F.: Propagation and reflection of gravity waves in a meridionally sheared wind field, J. Geophys. Res., 113, D09106, doi:10.1029/2007JD008877, 2008.

Huang, K. M., Zhang, S. D., and Yi, F.: Reflection and transmission of atmospheric gravity waves in a stably sheared horizontal wind field, J. Geophys. Res., 115, D16103, doi:10.1029/2009JD012687, 2010.
Huang, K. M., Liu, A. Z., Zhang, S. D., Yi, F., Huang, C. M., Gan, Q., Gong, Y., and Zhang, Y. H.: A nonlinear interaction event between a 16-day wave and a diurnal tide from meteor radar observations, Ann. Geophys., 31, 2039-2048, doi:10.5194/angeo31-2039-2013, 2013a.

Huang, K. M., Liu, A. Z., Lu, X., Li, Z., Gan, Q., Gong, Y., Huang, C. M., Yi, F., and Zhang, S. D.; Nonlinear coupling between quasi 2 day wave and tides based on meteor radar observations at Maui, J. Geophys. Res.-Atmos., 118, 10936-10943, doi:10.1002/jgrd.50872, 2013b.

Huang, K. M., Zhang, S. D., Yi, F., Huang, C. M., Gan, Q., Gong, Y., and Zhang, Y. H.: Nonlinear interaction of gravity waves in a nonisothermal and dissipative atmosphere, Ann. Geophys., 32, 263-275, doi:10.5194/angeo-32-263-2014, 2014.

Jacobi, C.: On the solar cycle dependence of winds and planetary waves as seen from mid-latitude D1 LF mesopause region wind measurements, Ann. Geophys., 16, 1534-1543, doi:10.1007/s00585-998-1534-3, 1998.

Jacobi, Ch., Portnyagin, Y. I., Merzlyakov, E. G., Kashcheyev, B. L., Oleynikov, A. N., Kürschner, D., Mitchell, N. J., Middleton, H. R., Muller, H. G., and Comley, V. E.: Mesosphere/lower thermosphere wind measurements over Europe in summer 1998, J. Atmos. Sol.-Terr. Phy., 63, 1017-1031, 2001.

Kalnay, E., Kanamitsu, M., Kistler, R., Collins, W., Deaven, D., Gandin, L., Iredell, M., Saha, S., White, G., Woollen, J., Zhu, Y., Chelliah, M., Ebisuzaki, W., Higgins, W., Janowiak, J., Mo, K. C., Ropelewski, C., Wang, J., Leetmaa, A., Reynolds, R., Jenne, R., and Joseph, D.: NCEP/NCAR 40-year reanalysis project, B. Am. Meteorol. Soc., 77, 437-471, 1996.

Kang, I.-S., Kim, D., and Kug, J.-S.: Mechanism for northward propagation of boreal summer intraseasonal oscillation: Convective momentum transport, Geophys. Res. Lett., 37, L24804, doi:10.1029/2010GL045072, 2010.

Krishnamurti, T. N. and Bhalme, H. N.: Oscillations of a monsoon system, Part I: Observational aspects, J. Atmos. Sci., 33, 19371954, 1976.

Krishnan, P., Kunhikrishnan, P. K., and Nair S. M.: Time-height evolution of intraseasonal oscillations in the tropical lower atmosphere: Multilevel wind observations using UHF radar, Geophys Res. Lett., 32, L07805, doi:10.1029/2004GL022019, 2005.

Kumar, K. and Jain, A. R.: Latitudinal variations of 30-70 day period waves over the tropical Indian zone, J. Atmos. Terr. Phys., 45, 1135-1145, 1994.

Lieberman, R. S.: Intraseasonal variability of high-resolution Doppler imager winds in equatorial mesosphere and lower thermosphere, J. Geophys. Res., 103, 11221-11228, doi:10.1029/98JD00532, 1998.

Liu, H.-L., Talaat, E. R., Roble, R. G., Lieberman, R. S., Riggin, D. M., and Yee, J.-H.: The 6.5-day wave and its seasonal variability in the middle and upper atmosphere, J. Geophys. Res., 109, D21112, doi:10.1029/2004JD004795, 2004.

Luo, Y., Manson, A. H., Meek, C. E., Igarashi, K., and Jacobi, Ch.: Extra long period (20-40 day) oscillations in the mesospheric and lower thermospheric winds: observations in Canada, Europe and Japan, and considerations of possible solar influences, J. Atmos. Sol.-Terr. Phy., 63, 835-852, 2001.

Madden, R. A. and Julian, P. R.: Detection of a 40-50 day oscillation in the zonal wind in the tropical Pacific, J. Atmos. Sci., 28, 702-708, 1971. 
Nagpal, O. P., Dhaka, S. K., and Srinivas, S. K.: Wave characteristics in the troposphere and stratosphere over the Indian tropics during the DYANA campaign, J. Atmos. Terr. Phys., 45, 11171133, 1994.

Pancheva, D., Mitchell, N. J., Younger, P. T., and Muller, H. G.: Intra-seasonal oscillation observed in the MLT region above UK $\left(52^{\circ} \mathrm{N}, 2^{\circ} \mathrm{W}\right)$ and ESRANGE $\left(68^{\circ} \mathrm{N}, 21^{\circ} \mathrm{E}\right)$, Geophys. Res. Lett., 30, 2084, doi:10.1029/2003GL017809, 2003.

Rao, D. N., Singh, H. R., Kulkarni, J. R., Chandrika, A. Y., and Rao, S. V. B.: Vertical variation of Madden-Julian oscillations in the normal monsoon season as revealed through MST radar wind data, Meteorol. Atmos. Phys., 73, 55-59, doi:10.1007/s007030050064, 2000.

Salby, M. L.: Survey of planetary-scale traveling waves: The state of theory and observations, Rev. Geophys., 22, 209-236, 1984.

Scargle, J. D.: Studies in astronomical time series analysis, II. Statistical aspects of spectral analysis of unevenly spaced data, Astrophysical J., 263, 835-853, 1982.
Takahashi, Y., Okazaki, Y., Sato, M., Miyahara, H., Sakanoi, K., Hong, P. K., and Hoshino, N.: 27-day variation in cloud amount in the Western Pacific warm pool region and relationship to the solar cycle, Atmos. Chem. Phys., 10, 1577-1584, doi:10.5194/acp-10-1577-2010, 2010.

Wu, D. L., Hays, P. B., and Skinner, W. R.: A least squares fitting method for spectral analysis of space-time series, J. Atmos. Sci. 52, 3501-3511, 1995.

Zhang, C.: Madden-Julian Oscillation, Rev. Geophys., 43, RG2003, doi:10.1029/2004RG000158, 2005.

Zhou, Q. H., Sulzer, M. P., and Tepley, C. A.: An analysis of tidal and planetary waves in the neutral winds and temperature observed at the E region, J. Geophys. Res., 102, 11491-11505, 1997. 